\title{
Combination of Minimum-Maximum (m-m) Attribute and Zero-INTENS-Difference (z-i-d) Attribute for Estimating Seismically Thin-Bed Thickness
}

\author{
Eko Widi Purnomo \& Zuhar Zahir Tuan Harith \\ Geoscience Program, Universiti Teknologi PETRONAS, Malaysia \\ Email: ekowidi@hotmail.com
}

\begin{abstract}
This paper demonstrates a new alternative way in estimating seismically thin-bed (below-tuning) thickness. Initial thickness is built by bandpass filtering the amplitude display of a zero-phase seismic. The filter removes the non minimum and or non maximum and left the maximum and or the minimum of seismic amplitude. The unresolved below-tuning thickness is then corrected by zero-INTENS-difference (z-i-d) attribute. INTENS is integrated energy spectra, an attribute which can be derived from spectral analysis. $\mathrm{z}$-i-d attribute is zero difference of INTENS between the seismic and its synthetic. The method generates INTENS difference profile by subtracting seismic INTENS and its synthetic INTENS iteratively. The iteration is controlled by dipole space shifting from distance to closer or vice versa. The true thickness is derived by locating z-i-d which laid in INTENS different profile. It has found that, for free noise true seismic and perfect-wavelet (a wavelet which only approximately similar with wavelet which constructing the true seismic) synthetic seismic, in INTENS different profile, the z-i-d location always corresponds to true dipole space or thickness. The method could resolve all thickness of a wedge-modeled seismic with three different dominant frequencies. When the synthetic seismic is constructed with imperfect wavelet, slightly different analysis is needed to locate $\mathrm{z}$-i-d attribute and the result is not as perfect as when perfect wavelet constructing synthetic seismic. A quiet similar result is got when the method is implemented for noisy wedge-modeled seismic. Bad thickness estimation is resulted for $20 \%$ noise seismic. The method algorithm is extended for similar dipole polarity model and multilayer model to bring the method to real seismic data nearer. The extension is done by estimating thickness of every layer of a stacked-wedge-modeled seismic. The algorithm then generalized for estimating layers thickness with several thickness combinations. The method was able to delineate shallow channel of Stratton Field by providing good pseudo-acousticimpedance (pseudo AI) map.
\end{abstract}

Keywords: below tuning; integrated energy spectra; intens; seismic attribute; seismic inversion; seismic resolution; spectral analysis; thin layer.

Received November $23^{\text {rd }} 2009$, Revised on October $23^{\text {rd }}, 2010$, Accepted for publication January $6^{\text {th }}, 2011$. 


\section{Introduction}

For decades, researchers have noticed that conventional seismic has a trouble when resolving the thickness of very thin layer. Researcher agreed that the thickness which can be resolved by conventional seismic is about $\lambda / 4$ and above, where $\lambda$ is predominant wavelength $[1,2]$. $\lambda / 4$ was known as tuning thickness. The recent study was reported by Zang [3]. It was claimed that tuning thickness will be unlimited for free noise data and can be as small as $\lambda / 16$ for real data which was acquired with current technology.

Russel [4] identified the effect of thin layer to the seismic inversion, a method which has claimed as the best tool for reservoir characterization. It was found that as the time separation between reflection the coefficient become smaller, the interference between overlapping wavelet become more severe. The effect is, the amplitude spectrum was altered as well as the phase spectrum. Russel [4] demonstrated recursive inversion and maximum likelihood deconvolution for a wedge modeled seismic to show the effect in practical. There were two dominant effects reported e.g. the two seismic inversion failed to resolve bed thickness below $\lambda / 4$ and the top wedge appeared 'pulled-up' at the traces near the edge of the wedge.

The improvement of seismic vertical resolution has also been tried in frequency domain [5-7]. Portniaguine and Castagna [8] inverted the reflectivity of thin bed by spectral inversion, a form of sparse-spike inversion in that it outputs a sparse reflectivity series. The result showed that spectral inversion is good when the data has high signal-to-noise but bad when the data has low signal-to-noise (noise level $0.01 \%$ and above. The inversion became noisy when using imperfect wavelet (a wavelet which is only approximately similar to wavelet constructing the true seismic).

In 2006, Puryear and Castagna [7] derived an algorithm for calculating a bed thickness from amplitude spectrum of the seismic. The algorithm was implemented for both modeled and real data. The result showed that the algorithm is robust for thick beds but noisy for very thin beds.

Liu and Marfurt [9] proposed thin-bed thickness prediction using peak instaneous frequency. The objective of the method is to improve the instaneous frequency method which was unstable and unreliable when the data have low signal-to-noise ratio. It was found that peak instaneous frequency was inversely proportional to the layer thickness and well-correlated with the layer thickness measured in the wells. But, it's less sensitive of peak instaneous frequency to the reflection coefficient changes, lead to its inverse trend become complicated for layer less than one eight wavelength thick. 
Hall [10] introduced cepstral, spectral of spectral, decomposition for predicting bed thickness. The thickness of layer are identified from the notch that periodically characterized by the spectral of the layer. Hall claimed that cepstral decomposition has the potential to significantly improve the accuracy of bed thickness estimation from seismic. But, Hall noted, that in the real data, estimating the periodic notch is difficult because the notch are commonly somewhat cryptic. Another weakness is, cepstrum is unfamiliar to most seismic interpreter although it is well-known in several other branches of signal processing.

This paper proposes the alternative way in estimating layer thickness by combining the minimum-maximum (will be called as $\mathrm{m}-\mathrm{m}$ ) and zero-INTENSdifference (will be called as z-i-d) attribute. The estimation of layer thickness below tuning thickness will be demonstrated. The $\mathrm{m}-\mathrm{m}$ attribute is derived by band-pass filtering the amplitude display. Z-i-d is derived by subtracting the integrated energy spectral (INTENS) of synthetic by the INTENS of the original seismic. It will be shown that combination of two attribute above can be used as layer thickness estimator.

\section{2 m-m Attribute}

Assuming that seismic is normal incident and zero phase, the reflectivity is in coincide with minimum or maximum amplitude of seismic signature. Peaking only the maximum and or minimum of seismic, the spike can be got. It can be simply done by band-pass filtering the amplitude display of seismic. The non maximum and or non minimum of amplitude display are removed and the maximum and or minimum amplitude are left. The 'new' attribute named $\mathrm{m}-\mathrm{m}$ attribute. Figure 1 shows the minimum-maximum (m-m) attribute of an opposite-polarity pair of dipole seismic. It is shown that the $\mathrm{m}-\mathrm{m}$ attribute accurately resolve the dipole space or thickness. But, unlike a common seismic inversion, $\mathrm{m}-\mathrm{m}$ attribute provide 'wrong' reflectivity magnitude. The pseudoreflectivity could be another name of $\mathrm{m}-\mathrm{m}$ attribute. This paper will only take the benefit of $\mathrm{m}-\mathrm{m}$ attribute in accurately resolving the thickness of the dipole.

The $\mathrm{m}-\mathrm{m}$ attribute can be extended for more than two reflectors (dipole) by adjusting the band of filter according to geology or earth-model to be considered. It will also make the broadband frequency of seismic accessible by m-m attribute. 

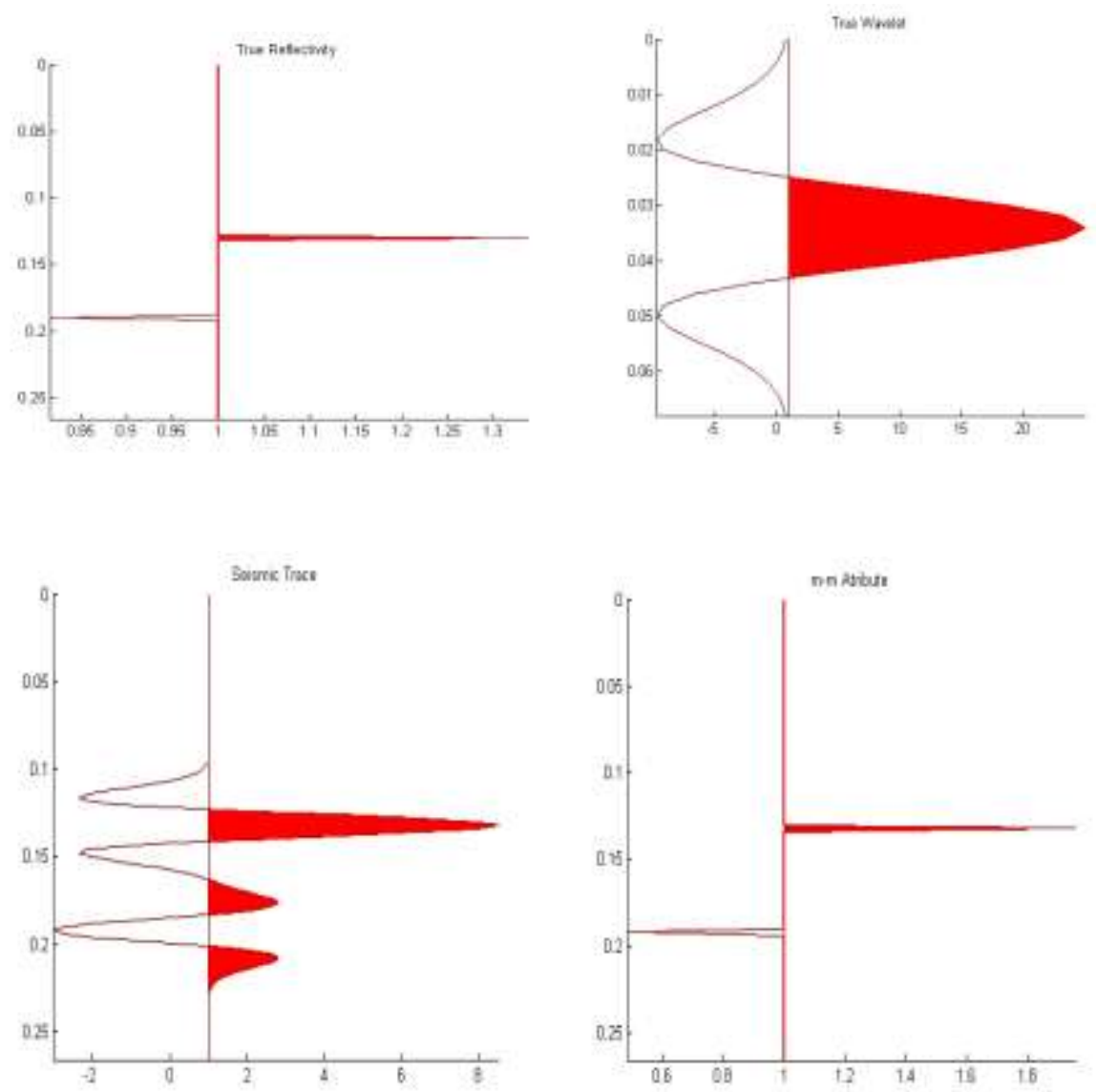

Figure $1 \mathrm{~m}-\mathrm{m}$ attribute $\left(2^{\text {nd }}\right.$ column $2^{\text {nd }}$ row $)$ from seismic $\left(1^{\text {st }}\right.$ column $2^{\text {nd }}$ row $)$ built from reflectivity ( $1^{\text {st }}$ column $1^{\text {st }}$ row) convolved with $25 \mathrm{~Hz}$ dominant frequency, 2 ms sampling rate and 35 wavelength Ricker wavelet $\left(2^{\text {nd }}\right.$ column $1^{\text {st }}$ row).

Figure 2 shows the m-m attribute of wedge modeled seismic resulted from convolution the model reflectivity with Ricker wavelet from $25 \mathrm{~Hz}$ dominant frequency, 2 ms sampling rate and 35 wavelengths $\left(2^{\text {nd }}\right.$ column Figure 1). From Chung and Lawton [11], the tuning thickness of the seismic is $15.6 \mathrm{~ms}$ located near trace 13 of the seismic section. 

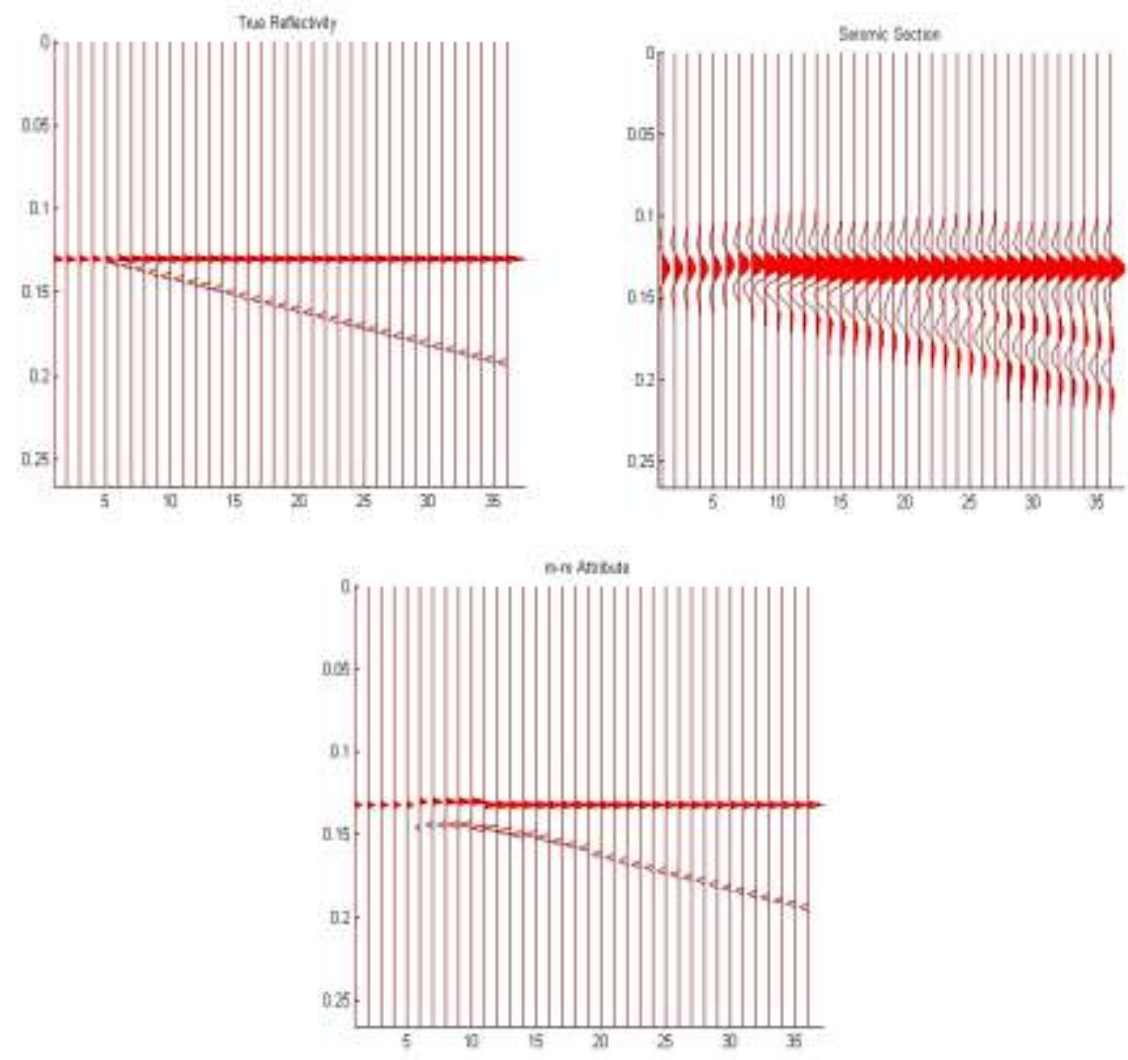

Figure $2 \mathrm{~m}-\mathrm{m}$ attribute ( $2^{\text {nd }}$ row) of wedge modelled seismic $\left(2^{\text {nd }}\right.$ column 1 st row) of wedge modeled reflectivity $\left(1^{\text {st }}\right.$ column).

It is showed that, in term of positioning the reflector, $\mathrm{m}-\mathrm{m}$ attribute displays fairly similar layer thickness to which displayed by spectral inversion $[7,8]$. With this performance and its simple process, $\mathrm{m}-\mathrm{m}$ attribute is chosen to be starting process of estimating the thickness of layer when it went below tuning.

Because m-m attribute will pick the peak and/or trough of seismic as 'reflectivity-like' spike, the method requires or will only work with zero-phase seismic. Every non zero-phase seismic has to be transformed to zero-phase one before the $\mathrm{m}-\mathrm{m}$ attribute is extracted.

The sample rate interval is another important factor for $\mathrm{m}$-m attribute. It will be the thinnest thickness which m-m attribute can resolve. However, a thickness thinner than sample rate interval can be obtain if seismic re-sampling is allowable. 


\section{Integrated Energy Spectra (INTENS)}

Integrated Energy Spectra (INTENS) is a form of frequency domain analysis which firstly introduced by Marangakis, et al. [12]. INTENS is defined as integrated partial energy plotted against frequency. Mathematically, INTENS of a time series data at frequency $f$ is defined as:

$$
E(f)=100 \int_{f l}^{f u} A(f) A^{*}(f) d f / \int_{f l}^{f} A(f) A^{*}(f) d f
$$

where $A(f)$ and $A^{*}(f)$ are the amplitude spectra of the time series at frequency $f$ and the conjugate consecutively. $\mathrm{fl}$ and fu is the lowest and highest frequency range consecutively.
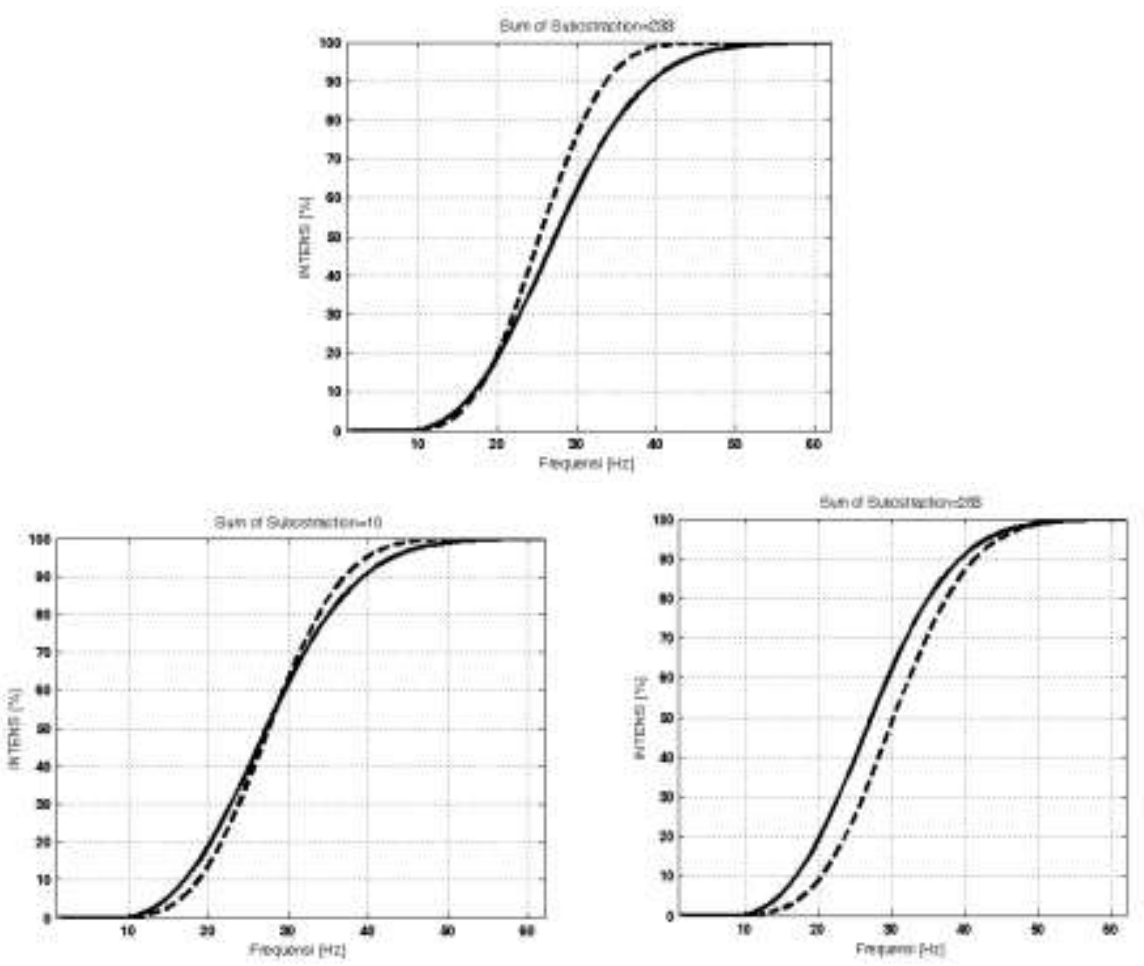

Figure 3 Seismogram (dash line)-wavelet (full line) INTENS comparison. When thickness greater than tuning ( ${ }^{\text {st }}$ row); thickness closely to tuning (1st column 2 nd row) and thickness under tuning ( $2^{\text {nd }}$ column $2^{\text {nd }}$ row) (recalculated after Marangakis, et al. [12]). 
INTENS can be applied to any time series data. Two INTENS of two time series data can be compared for further study or analysis. Figure 3 shows graphical comparison of a dipole seismic and its applied wavelet.

It is showed that when the thickness of dipole is close to the tuning thickness, the INTENS of seismic is nearly similar to which of the wavelet.

It was indicated that INTENS was consistently changing whatever close the dipole spaces or whatever seismically thin the layer will. INTENS is claimed as a good layer thickness identifier [12].

\section{How INTENS Can Help Layer Thickness Estimation}

The previous INTENS studies leads to a hypothesis: the INTENS of a synthetic seismic has to be similar to its true seismic. The better synthetic seismic the less INTENS difference.

To prove the hypothesis, the previous $\mathrm{m}-\mathrm{m}$ attribute study is recalled. The trace 6 of $\mathrm{m}-\mathrm{m}$ attribute study at Figure 2 will be used as a sample. The trace 6 has true thickness 1 sample rate interval (sri) and m-m attribute 7 sri. The following are the process run:

1. The INTENS of trace 6 of true seismic $\left(2^{\text {nd }}\right.$ column Figure 2$)$ is calculated

2. The synthetic seismic of trace 6 is built by convolving the trace 6 of $\mathrm{m}-\mathrm{m}$ attribute $\left(2^{\text {nd }}\right.$ row Figure 2$)$ with the true wavelet $\left(2^{\text {nd }}\right.$ column Figure 1$)$

3. The INTENS of synthetic seismic (step 2) is calculated

4. The INTENS of synthetic seismic (step 3) is subtracted by the INTENS of true seismic ( step 1)

5. The space of $\mathrm{m}-\mathrm{m}$ attribute of trace 6 is contracted 1 thickness interval shorter

6. Step 2, 3 and 4 are repeated

7. Step 5 and 6 are repeated until the space of $m-m$ attribute is 1 thickness interval.

Table 1 displays INTENS observation of the modeled seismic. It is shown that the 0 (zero) value of INTENS-difference between the synthetic and its true seismic points to the true thickness of wedge.

Table 2 and Figure 4 shows the result of INTENS observation for traces below tuning (trace 6 to 12) of the wedge model. Table 2 informs clearly that 0 (zero) value of INTENS-difference always points the true thickness. Figure 4 also gives the same information although 2 pairs of plot ( 8 and 9,11 and 7$)$ nearly close each other. 
Tabel 1 INTENS Difference of Trace 6 of seismic $\left(2^{\text {nd }}\right.$ column Figure 2).

\begin{tabular}{cc}
\hline $\begin{array}{c}\text { Dipole Thickness } \\
\text { (sri) }\end{array}$ & INTENS Difference \\
\hline 1 & 0 \\
2 & -165.0921 \\
3 & -234.9346 \\
4 & -241.1266 \\
5 & -211.6287 \\
6 & -159.3323 \\
7 & -90.6405 \\
\hline
\end{tabular}

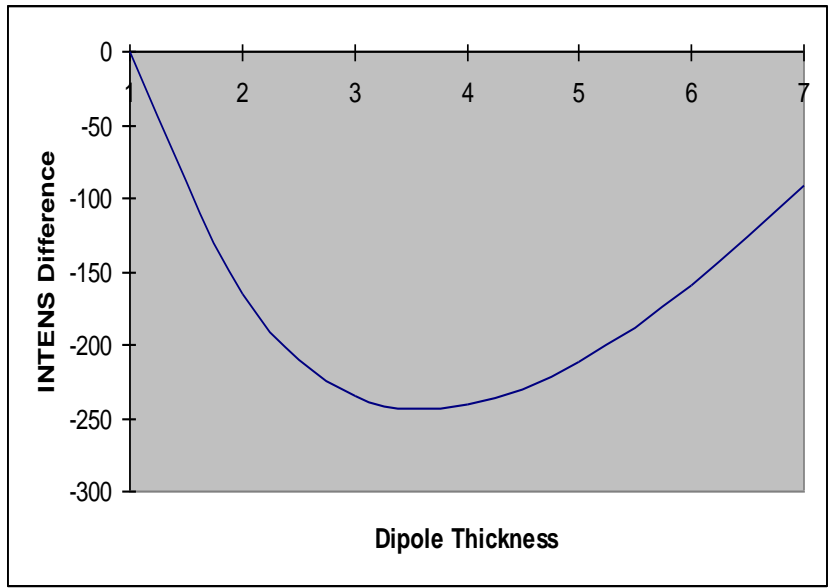

Figure 4 INTENS Difference vs Thickness of Trace 6.

Tabel 2 INTENS-Difference of Traces below tuning of wedge modeled seismic. It is showed that zero INTENS difference point to true thickness.

\begin{tabular}{|c|c|c|c|c|c|c|c|}
\hline \multirow{2}{*}{$\begin{array}{c}\text { Dipole } \\
\text { True } \\
\text { Thickness } \\
\text { (sri) }\end{array}$} & \multicolumn{7}{|c|}{ INTENS Difference } \\
\hline & $\begin{array}{c}\text { Trace } 6 \\
\text { m-m att. } \\
7 \text { sri }\end{array}$ & $\begin{array}{c}\text { Trace } 7 \\
\text { m-m att. } \\
6 \text { sri }\end{array}$ & $\begin{array}{c}\text { Trace } 8 \\
\text { m-m att. } \\
6 \text { sri }\end{array}$ & $\begin{array}{c}\text { Trace } 9 \\
\text { m-m att. } \\
6 \text { sri }\end{array}$ & $\begin{array}{c}\text { Trace } 10 \\
\text { m-m att. } \\
\quad 6 \text { sri }\end{array}$ & $\begin{array}{c}\text { Trace } 11 \\
\text { m-m att. } \\
7 \text { sri }\end{array}$ & $\begin{array}{c}\text { Trace } 12 \\
\text { m-m att. } \\
7 \text { sri }\end{array}$ \\
\hline 1 & 0 & 165.09 & 234.93 & 241.12 & 211.62 & 159.33 & 90.64 \\
\hline 2 & -165.09 & 0 & 69.84 & 76.03 & 46.53 & -5.75 & -74.45 \\
\hline 3 & -234.93 & -69.84 & 0 & 6.19 & -23.30 & -75.60 & -144.29 \\
\hline 4 & -241.12 & -76.03 & -6.19 & 0 & -29.49 & -81.79 & -150.48 \\
\hline 5 & -211.62 & -46.53 & 23.30 & 29.49 & 0 & -52.29 & -120.98 \\
\hline 6 & -159.33 & 5.759 & 75.60 & 81.79 & 52.29 & 0 & -68.69 \\
\hline 7 & -90.64 & & & & & 68.69 & 0 \\
\hline
\end{tabular}


Figure 5 summarizes the 'full-work' of layer thickness estimation by combining $\mathrm{m}-\mathrm{m}$ and $\mathrm{z}-\mathrm{i}-\mathrm{d}$ attribute. To make a better calculation, the true reflectivity magnitude is restored to $\mathrm{m}-\mathrm{m}$ attribute map before synthetic seismic is built. The step is done because, actually, the reflectivity magnitude is not changed at below tuning zone. In real world, true reflectivity can be got from well log data.

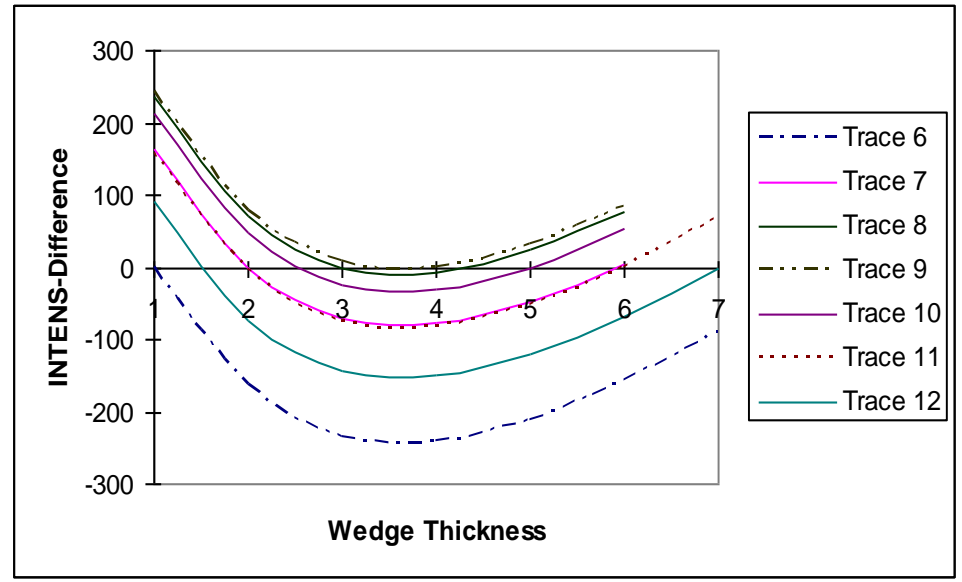

Figure 5 INTENS-Difference of Traces below-tuning of modeled wedge.

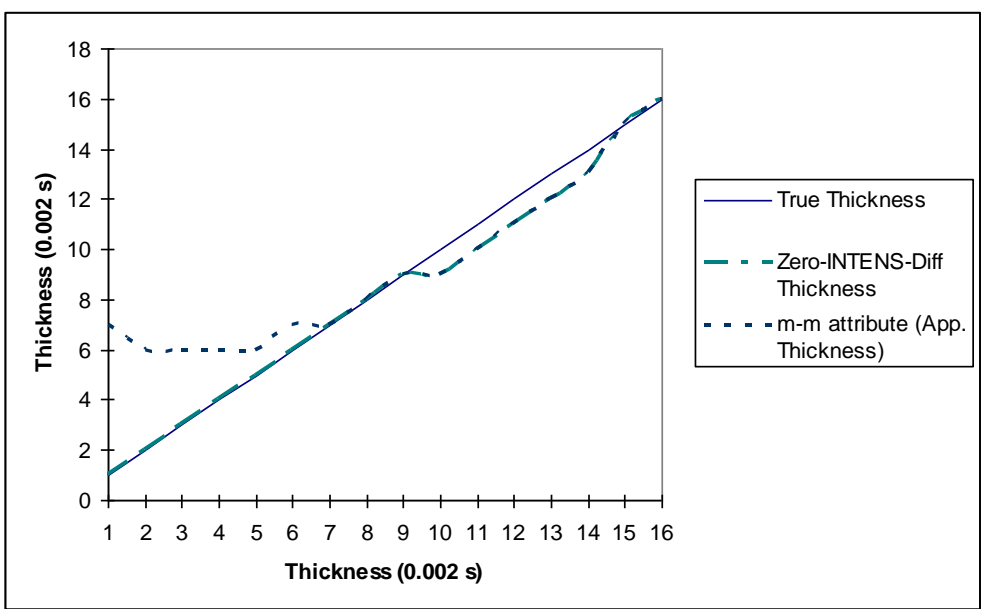

Figure $6 \mathrm{~m}-\mathrm{m}$ Attribute, Zero-INTENS-Difference and True Thickness relationship.

Figure 6 illustrates the relationship between true thickness, apparent thickness ( $\mathrm{m}-\mathrm{m}$ attribute) and zero-INTENS-difference thickness. It is shown that, below tuning zone, zero-INTENS-difference accurately point to the true thickness. At the tuning zone, the apparent thickness ( $\mathrm{m}-\mathrm{m}$ attribute) and zero-INTENS- 
difference thickness coincide with true thickness. At the zone between tuning and twice tuning, the apparent thickness ( $\mathrm{m}-\mathrm{m}$ attribute) and zero-INTENSdifference thickness drop 1 thickness interval below true thickness.

Based on model information, the top reflector is corrected from 'pulled-up' effect. Perfect (noise free) data and perfect wavelet make the method work perfectly.
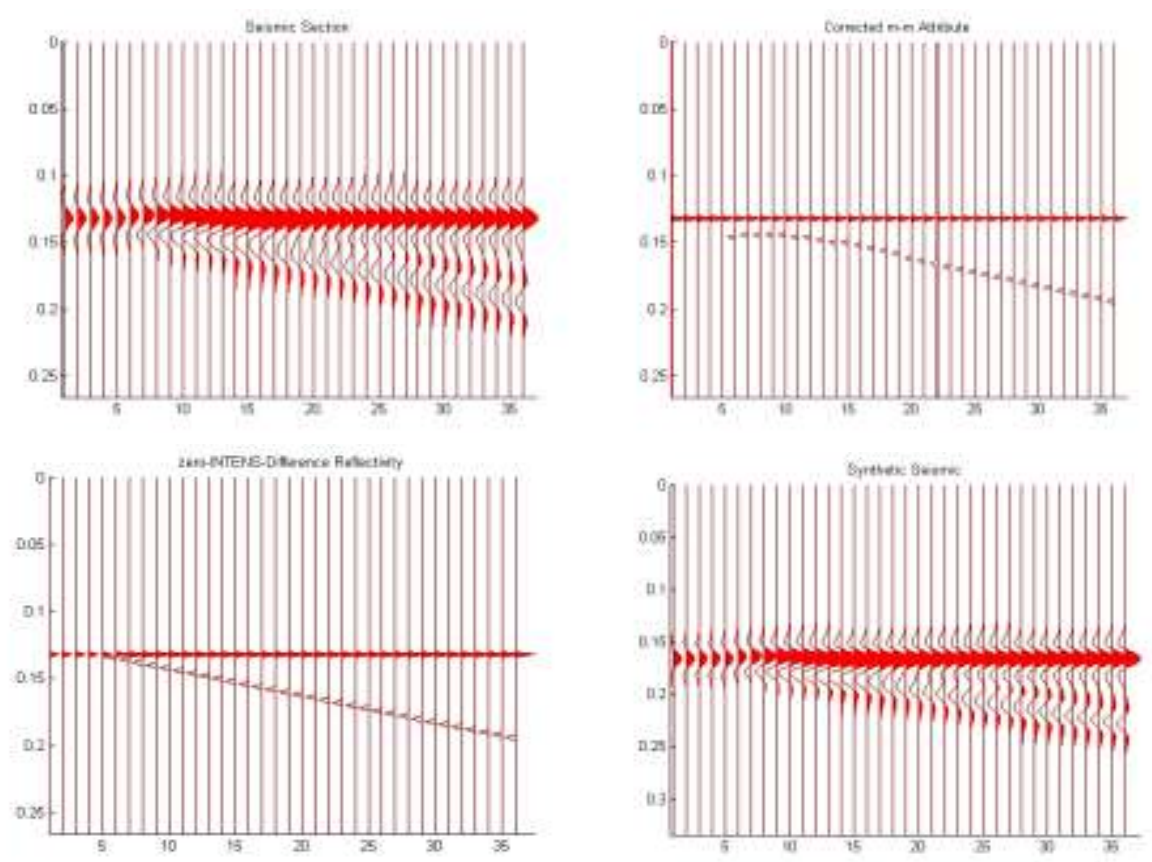

Figure 7 The final result of wedge modeled seismic thickness estimation. The true seismic $\left(1^{\text {st }}\right.$ row $1^{\text {st }}$ column$)$, the $\mathrm{m}-\mathrm{m}$ attribute thickness initial estimation ( $2^{\text {nd }}$ column $1^{\text {st }}$ row $)$, the $\mathrm{z}$-i-d attribute finalized estimation $\left(1^{\text {st }}\right.$ column $2^{\text {nd }}$ row $)$ and the synthetic seismic ( $2^{\text {nd }}$ column $2^{\text {nd }}$ row).

\section{$5 \quad$ Effect of Dominant Frequency}

Frequency takes important role in seismic exploration. To observe how affected the proposed method by frequency, two wedge modeled seismic with lower and higher dominant frequency have used as sample. The first is wedge modeled seismic with $20 \mathrm{~Hz}$ of dominant frequency $(19,5 \mathrm{~ms}$ of tuning thickness) and the other is wedge modeled seismic with $30 \mathrm{~Hz}$ of dominant frequency $(13 \mathrm{~ms}$ of tuning thickness). 

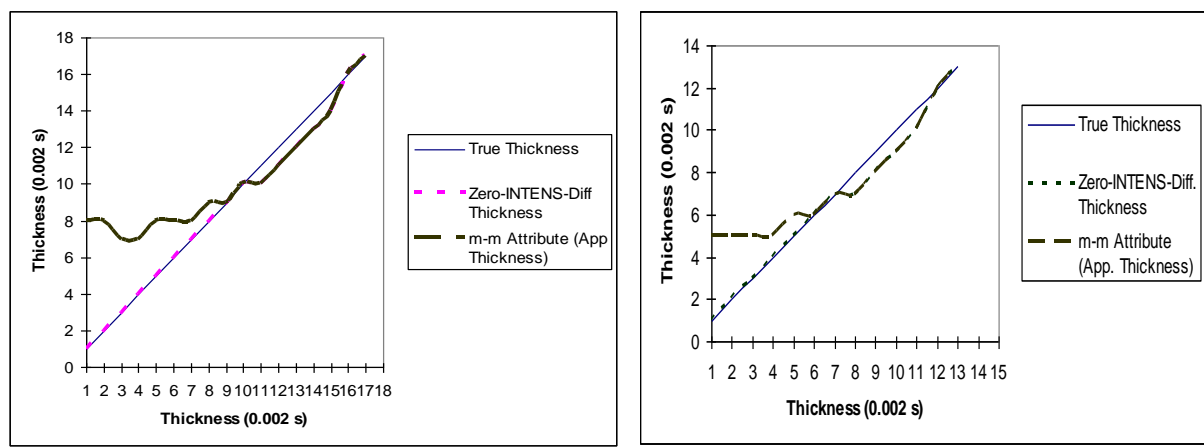

Figure 8 m-m Attribute, $\mathrm{z}-\mathrm{i}-\mathrm{d}$ and true thickness relationship for $20 \mathrm{~Hz}$-wedgemodeled seismic (left) and $30 \mathrm{~Hz}$-wedge-modeled seismic (right).
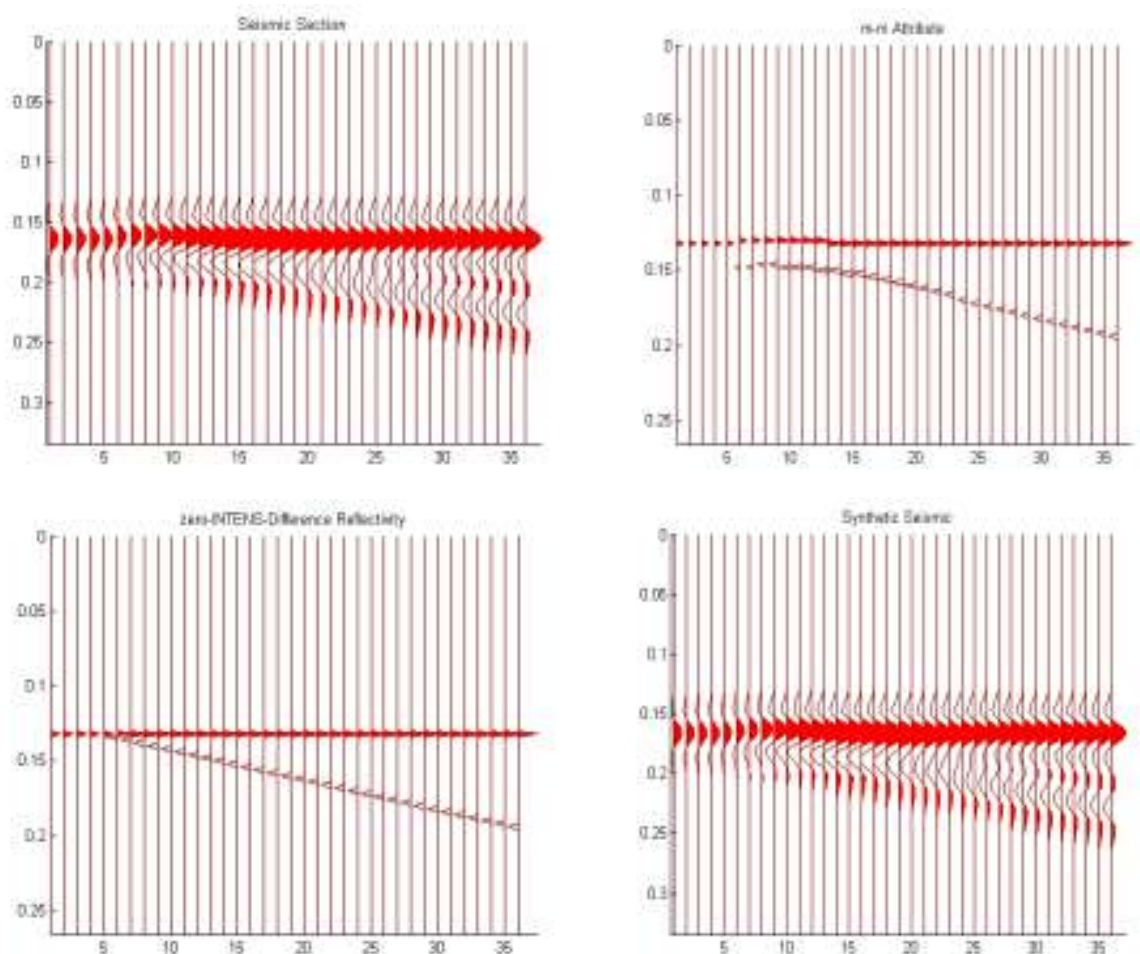

Figure 9 Thickness estimation of 20Hz-wedge-modeled seismic. True seismic $\left(1^{\text {st }}\right.$ row $1^{\text {st }}$ column $), \mathrm{m}-\mathrm{m}$ attribute thickness $\left(1^{\text {st }}\right.$ row $2^{\text {nd }}$ column $), \mathrm{z}-\mathrm{i}-\mathrm{d}$ attribute thinckness $\left(2^{\text {nd }}\right.$ row $1^{\text {st }}$ column $)$, and synthetic seismic ( $2^{\text {nd }}$ row $2^{\text {nd }}$ column $)$.

Figure 8 illustrates the relationship between true thickness, m-m attribute and zi-d thickness of wedge-modeled seismic with $20 \mathrm{~Hz}$ dominant frequency (first column) and wedge-modeled seismic with $30 \mathrm{~Hz}$ dominant frequency. 
Comparing to previous $25 \mathrm{~Hz}$ graphic, the z-i-d thickness curve of all of three are similar in trend and has similar position regarding to their true thickness. It can be concluded that $\mathrm{m}-\mathrm{m}$ and $\mathrm{z}-\mathrm{i}-\mathrm{d}$ attribute combination is not sensitive to dominant frequency of seismic.

Figure 9 and Figure 10 depict the result of thickness estimation of $20 \mathrm{~Hz}$ and 30 $\mathrm{Hz}$ wedge modeled seismic respectively. It is shown that there is no significant difference between the last two results with the first (25Hz seismic model).
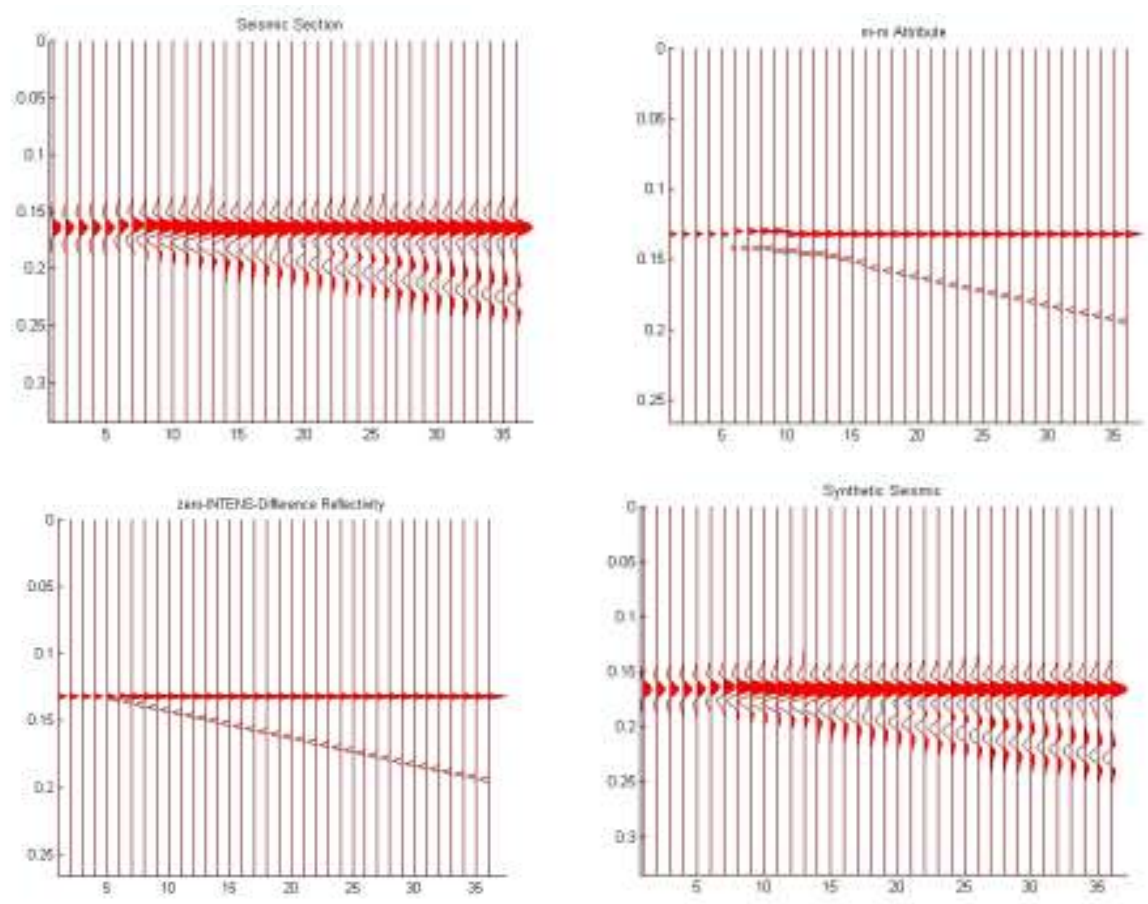

Figure 10 Thickness estimation of $30 \mathrm{~Hz}$ wedge modeled seismic. True seismic $\left(1^{\text {st }}\right.$ row $1^{\text {st }}$ column $), m-m$ attribute thickness $\left(1^{\text {st }}\right.$ row $2^{\text {nd }}$ column $), z-i-$ $\mathrm{d}$ attribute thinckness $\left(2^{\text {nd }}\right.$ row $1^{\text {st }}$ column $)$, and synthetic seismic $\left(2^{\text {nd }}\right.$ row $2^{\text {nd }}$ column).

\section{Effect of Imperfect Wavelet}

To observe how close the method to the real world, an imperfect wavelet has been used to estimate the layer thickness replacing the perfect one. A wavelet was extracted from trace 35 of the $25 \mathrm{~Hz}$ wedge modeled seismic by S4M ${ }^{\mathrm{TM}}$ 's s_seismic2wavelet MatLab ${ }^{\mathrm{TM}}$ routine code, Figure 11. The wavelet is called imperfect because of its dissimilarity with the true or perfect wavelet (wavelet 
which constructing true seismic). The thickness estimation, then, is done as previously done for the perfect wavelet. The result is tabulated in Table 3.

Problem arises at the Table 3 because there is no zero value of INTENS difference which can be used as true thickness indicator. Otherwise the minimum absolute value of INTENS-difference, which always zero for perfect wavelet cases, does not point a consistent thickness. To see more, how imperfect wavelet affect $\mathrm{z}-\mathrm{i}-\mathrm{d}$ thickness prediction, the minimum absolute INTENS difference is plotted, Figure 13.

Tabel 3 INTENS Difference of $25 \mathrm{~Hz}$-wedge-modeled seismic when the synthetic seismic constructed using extracted wavelet. There is no $\mathrm{z}-\mathrm{i}-\mathrm{d}$ attribute showed.

\begin{tabular}{|c|c|c|c|c|c|c|c|}
\hline \multirow[b]{2}{*}{$\begin{array}{c}\text { Dipole } \\
\text { True } \\
\text { Thickness } \\
\text { (sri) }\end{array}$} & \multicolumn{7}{|c|}{ INTENS Difference } \\
\hline & $\begin{array}{c}\text { Trace } 6 \\
\text { m-m att. } 7 \\
\text { sri }\end{array}$ & $\begin{array}{c}\text { Trace } 7 \\
\text { m-m att. } \\
6 \text { sri }\end{array}$ & $\begin{array}{c}\text { Trace } 8 \\
\text { m-m att. } 6 \\
\text { sri }\end{array}$ & $\begin{array}{c}\text { Trace } 9 \\
\text { m-m att. } \\
6 \text { sri }\end{array}$ & $\begin{array}{c}\text { Trace } 10 \\
\text { m-m att. } \\
6 \text { sri }\end{array}$ & $\begin{array}{c}\text { Trace } 11 \\
\text { m-m att. } \\
7 \text { sri }\end{array}$ & $\begin{array}{c}\text { Trace } 12 \\
\text { m-m att. } \\
7 \text { sri }\end{array}$ \\
\hline 1 & -21.06 & 144.03 & 213.87 & 220.06 & 190.57 & 138.27 & 69.58 \\
\hline 2 & -210.45 & -45.36 & 24.49 & 30.68 & 1.18 & -51.11 & -119.81 \\
\hline 3 & -287.03 & -121.93 & -52.09 & -45.90 & -75.40 & -127.69 & -196.39 \\
\hline 4 & -288.27 & -123.18 & -53.34 & -47.14 & -76.64 & -128.94 & -197.63 \\
\hline 5 & -248.15 & -83.06 & -13.22 & -7.03 & -36.52 & -88.82 & -157.51 \\
\hline 6 & -183.19 & -18.09 & 51.75 & 57.94 & 28.44 & -23.85 & -92.55 \\
\hline 7 & -102.31 & & & & & 57.03 & -11.67 \\
\hline
\end{tabular}

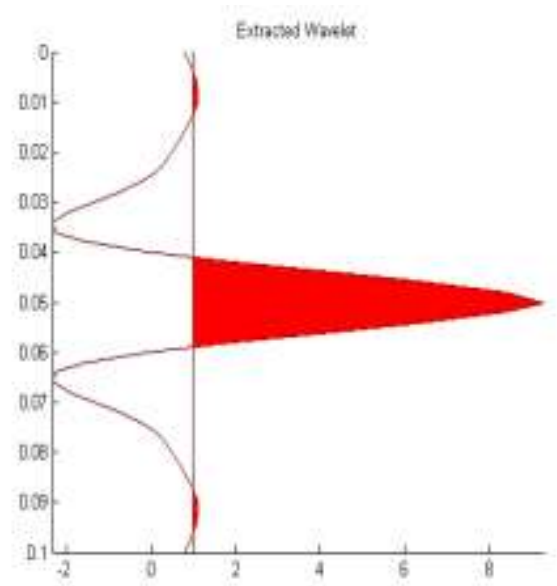

Figure 11 Extracted wavelet from trace 35 25Hz-wedge-modeled seismic. 


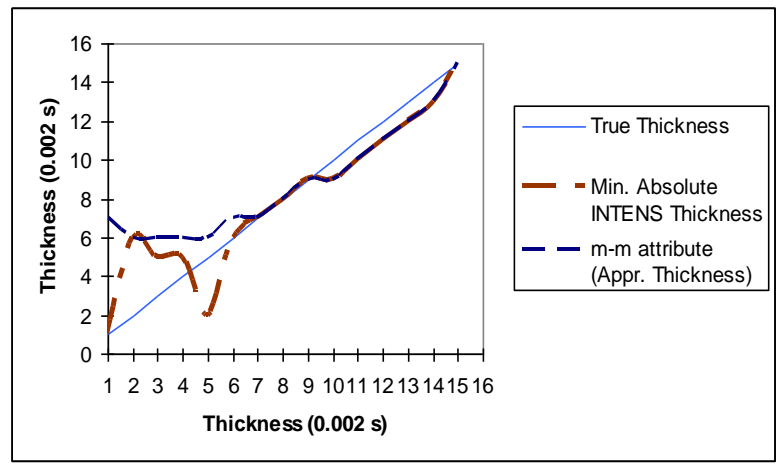

Figure 12 Effect of imperfect wavelet to minimum Absolute INTENS difference ( $z-\mathrm{i}-\mathrm{d}$ in perfect wavelet case) thickness prediction. It is showed that only the zone below tuning affected by imperfect wavelet.

It is shown by Figure 12, that only the zone below tuning affected by imperfect wavelet. The tuning zone and above, the minimum-Absolute-INTENSdifference is still follow the z-i-d trend or not affected by imperfect wavelet. Although, it is still difficult to predict the true thickness either from the graph or from table.

But, if it is tried to find out where the zero value inside or nearest the profile, it will be realized that the zero value is located near the value which point the true thickness. Figure 13 will help the observation.

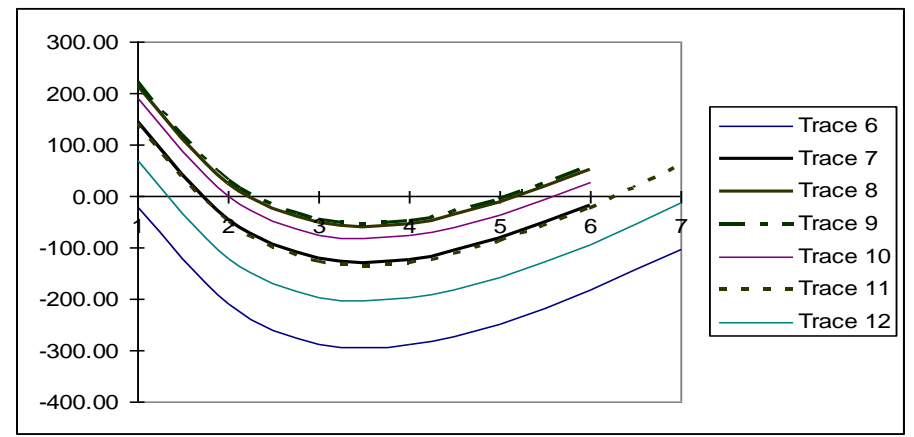

Figure 13 INTENS-Difference profile of $25 \mathrm{~Hz}$ wedge modeled seismic when the synthetic seismic is constructed with imperfect wavelet

Attention has to be taken when deciding which zero position should be chosen as true thickness estimation guide. Because of parabolic pattern of the profile, there are 2 zero position exists. It is proposed to use additional parameters to 
help decision making. That is $\mathrm{m}-\mathrm{m}$ attribute ratio. $\mathrm{m}-\mathrm{m}$ attribute ratio is ratio between the $m-m$ attribute and corrected $m-m$ attribute ( $m-m$ attribute after the true or tuning reflectivity restored in). Figure 14 illustrate the relationship between minimum-absolute-INTENS-difference, $\mathrm{m}$-m attribute, $\mathrm{m}$-m attribute ratio and true thickness.

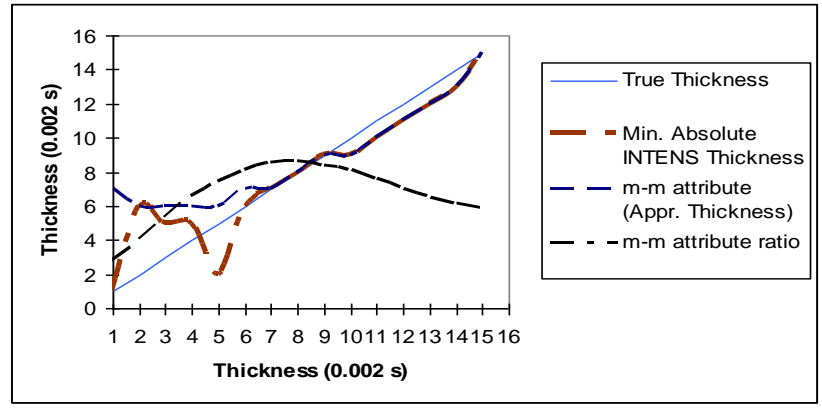

Figure 14 The relation of minimum-absolute-INTENS-difference, m-m attribute, $m-m$ attribute ratio and true thickness.
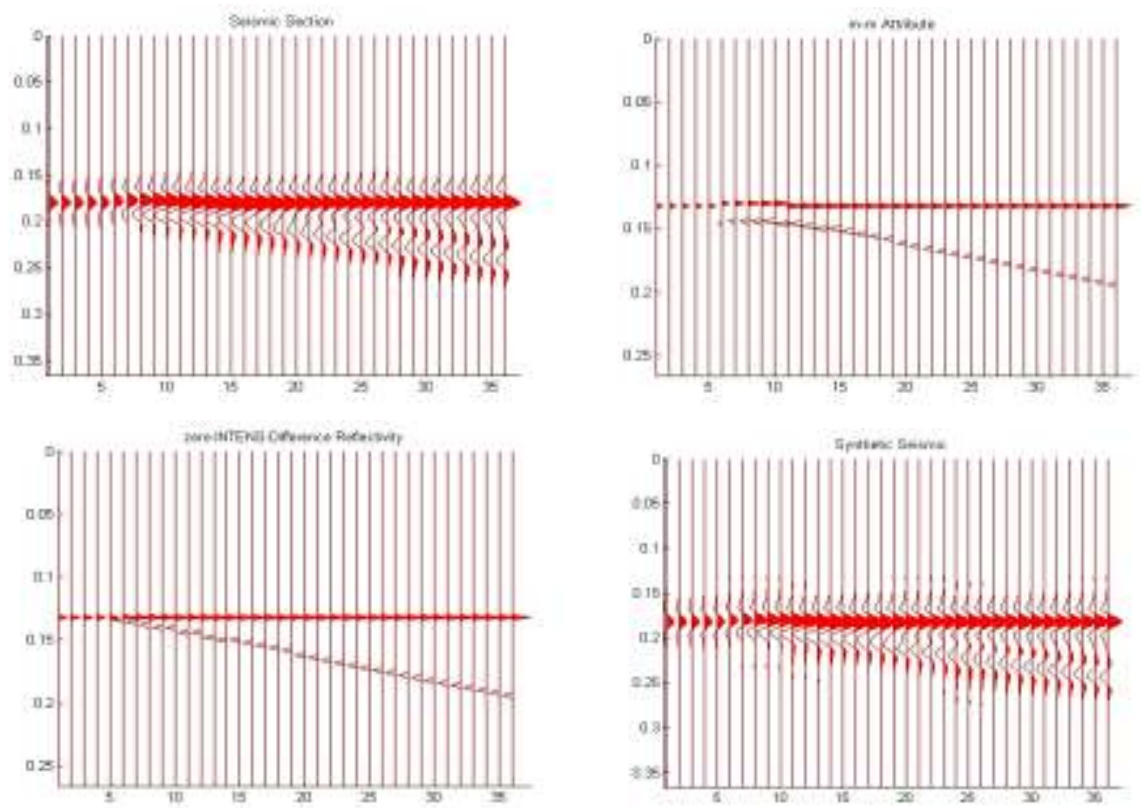

Figure 15 Result of thickness estimation of $25 \mathrm{~Hz}$-wedge-modeled seismic when imperfect wavelet (Figure 11) is used to construct the synthetic seismic.

The true thickness will be estimated as the thickness which pointed by first zero when the $\mathrm{m}-\mathrm{m}$ ratio is below the $\mathrm{m}-\mathrm{m}$ attribute or apparent thickness and will be 
the thickness pointed by second zero if the $\mathrm{m}-\mathrm{m}$ ratio is above the $\mathrm{m}-\mathrm{m}$ attribute. Figure 15 shows the result of thickness estimation of $25 \mathrm{~Hz}$-wedgemodeled seismic when imperfect wavelet (Figure 11) is used to construct the synthetic seismic.

\section{$7 \quad$ Effect of Noise}

The method was implemented to invert the thickness of noisy wedge modeled seismic. The result is summarized in Figure 16. It is shown that up to the 10\% noise level data the method still gives a robust result but when the noise reach $20 \%$ the method gives noisy result.
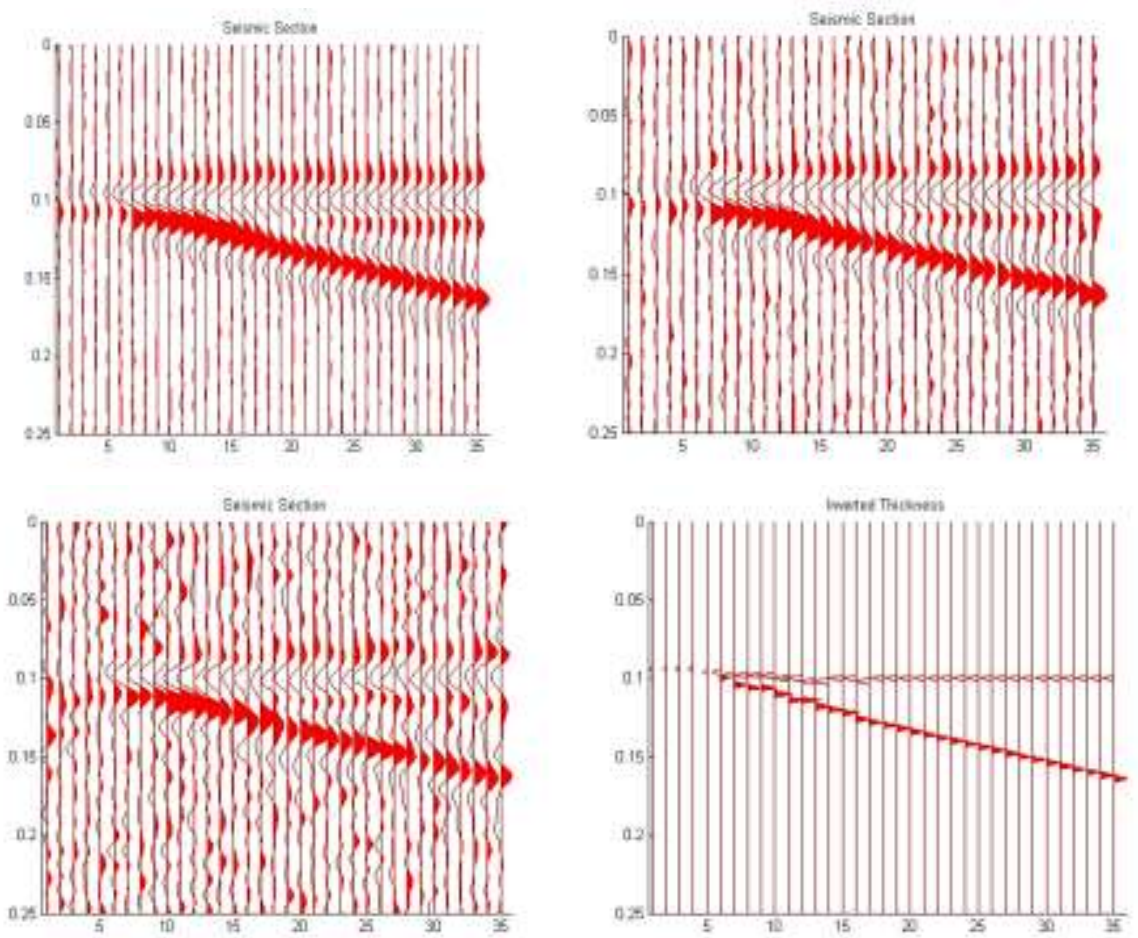

Figure 16 (continue) Thickness estimation of noisy-wedge-modelled seismic with $5 \%$ noise $\left(1^{\text {st }}\right.$ column $1^{\text {st }}$ row $), 10 \%$ noise $\left(2^{\text {nd }}\right.$ column $1^{\text {st }}$ row $), 20 \%$ noise $\left(1^{\text {st }}\right.$ column $2^{\text {nd }}$ row) and the estimated thickness for consecutively $5 \%$ noise $\left(2^{\text {nd }}\right.$ column $2^{\text {nd }}$ row), $10 \%$ noise $\left(1^{\text {st }}\right.$ column $3^{\text {rd }}$ row $), 20 \%$ noise $\left(2^{\text {nd }}\right.$ column $3^{\text {rd }}$ row). 

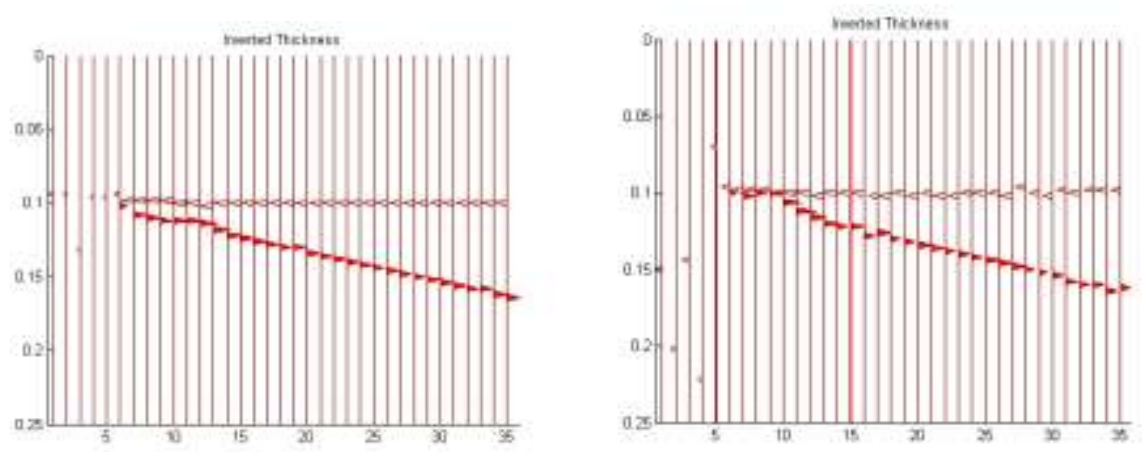

Figure 16 Thickness estimation of noisy-wedge-modelled seismic with 5\% noise $\left(1^{\text {st }}\right.$ column $1^{\text {st }}$ row $), 10 \%$ noise $\left(2^{\text {nd }}\right.$ column $1^{\text {st }}$ row $), 20 \%$ noise $\left(1^{\text {st }}\right.$ column $2^{\text {nd }}$ row) and the estimated thickness for consecutively $5 \%$ noise $\left(2^{\text {nd }}\right.$ column $2^{\text {nd }}$ row $), 10 \%$ noise $\left(1^{\text {st }}\right.$ column $3^{\text {rd }}$ row $), 20 \%$ noise $\left(2^{\text {nd }}\right.$ column $3^{\text {rd }}$ row).

\section{$8 \quad$ Similar Polarity and Multilayer Algorithm Extension}

The similar dipole polarity is modeled by inserting a similar spike near extracted $\mathrm{m}-\mathrm{m}$ attribute as test case. If the INTENS difference of the new $\mathrm{m}-\mathrm{m}$ attribute is smaller than its original, then the new m-m attribute is chosen as earth model, otherwise the original is kept as model.

The extension of the method for more than one thin layer model is done by analyzing matrices of INTENS different of every trace of seismic. When single layer model generates column matrices which length is equal to thickness variation numbers, hence multi layer model will generate L1xL2xL3........Ln matrices. Where L1, L2, L3, Ln are thickness variation number of layer 1, 2, 3 and $n$ consecutively. It can be imagine that inverting more than 3 layers will be very complicated.
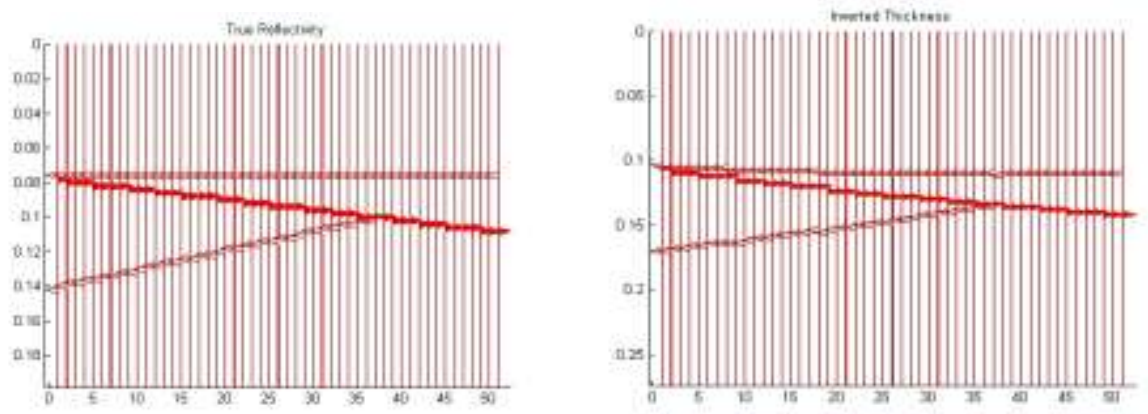

Figure 172 (two) layers model (left) and its inverted thickness (right). 
Simply, this paper analyzes INTENS different matrices of two layers model first.

Making easier analysis, the element of matrices are grouped by minimum different thickness between total thickness of layer thickness combination and its $\mathrm{m}-\mathrm{m}$ attribute, and minimum sum of thickness difference of every layer between thickness combination and its $m-m$ attribute. No simple or general pattern is found. The rules or algorithm for thickness determination is constructed with the guidance of model. Figure 18 shows the reflectivity model and its inverted thickness. Base on 2 layers model inversion, the 3 layers model algorithm is developed. Basically, 3 layers model inversion is an iterative one of 2 layers model inversion. The entire layers thickness inversion is done by estimating the thickness of every two consecutive layer. The result of previous two consecutive layer inversions is used to invert the next two consecutive layers. Figure 18 shows the 3 layer model and its inverted thickness.
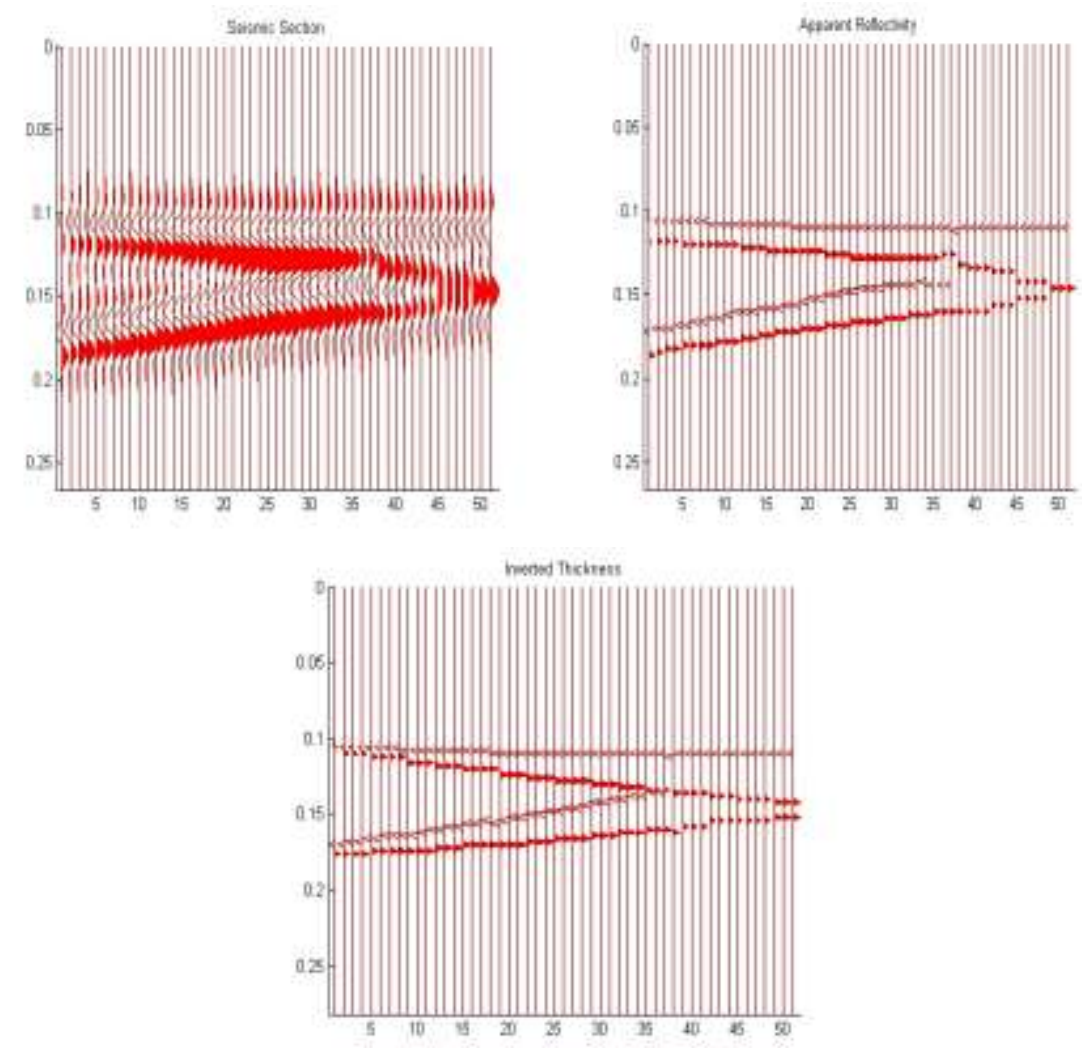

Figure 183 (three) layers model: seismic $\left(1^{\text {st }}\right.$ column $1^{\text {st }}$ row), m-m attribute $\left(2^{\text {nd }}\right.$ column $1^{\text {st }}$ row $)$ and its estimated thickness ( $2^{\text {nd }}$ row). 


\section{Real Data Implementation}

The extended algorithm is applied to Stratton Field seismic data, a public data provided by Texas Bureau of Economic Geology. This paper will focus on shallow region of Stratton Field where a channel structure appears at approximately $842 \mathrm{~ms}$ time-depth [6]. Figure 19 (left) is an amplitude time slice identifying the channel. A phase change is introduced across the time slice due to a gentle dip of the bed; however the channel can be clearly identified. Figure 19 (right) shows that a conventional horizon-picking time structure does not give a clear channel representation, although the channel is still visible.

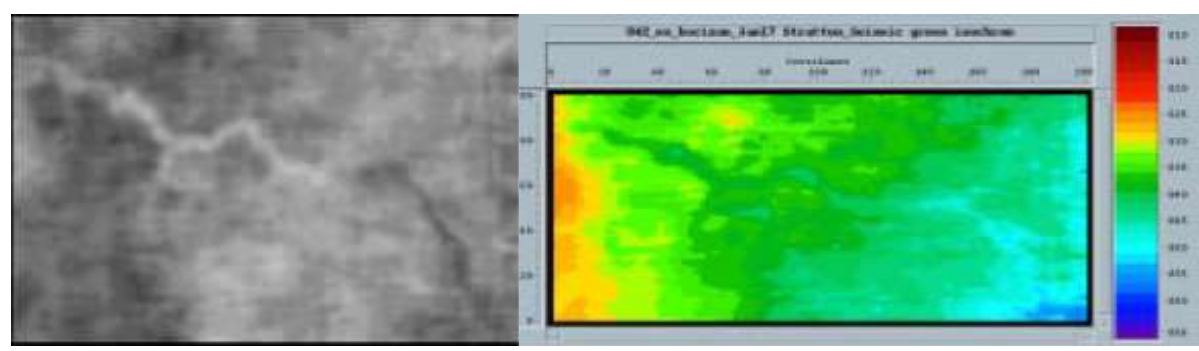

Figure 19 Amplitude time slice showing channel structure at shallow region of Stratton seismic (left) and structural (time) surface of picked horizon outlining the channel (right) (from Pennington [6]).
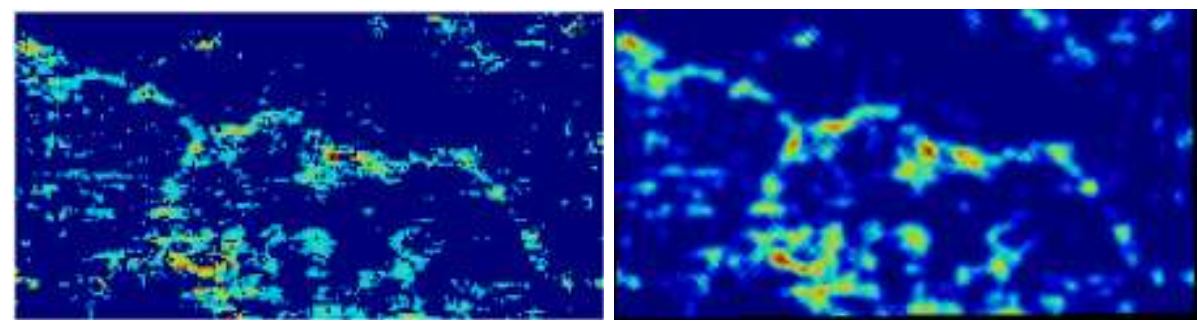

Figure 20 Stratton Shallow Region relative impedance time slice. Calculated by the method (left) and after estimated by kriging (right).

This paper estimate the time thicknesses and pseudo-reflectivity using combination of $\mathrm{m}-\mathrm{m}$ and $\mathrm{z}-\mathrm{i}-\mathrm{d}$ attribute. Then, calculate and map the relative impedance by assuming the top layer is water. Figure 6 shows contoured time slices of relative impedance volume of Stratton shallow region. When the volume is sliced horizontally, fewer channels part are represented with fewer noises (Figure 20 (right)). But when the volume is sliced deeply, more channel parts are represented however more noises are appear. The more channel parts representation conform the amplitude time slice including dipping bed introduced by phase changes. 


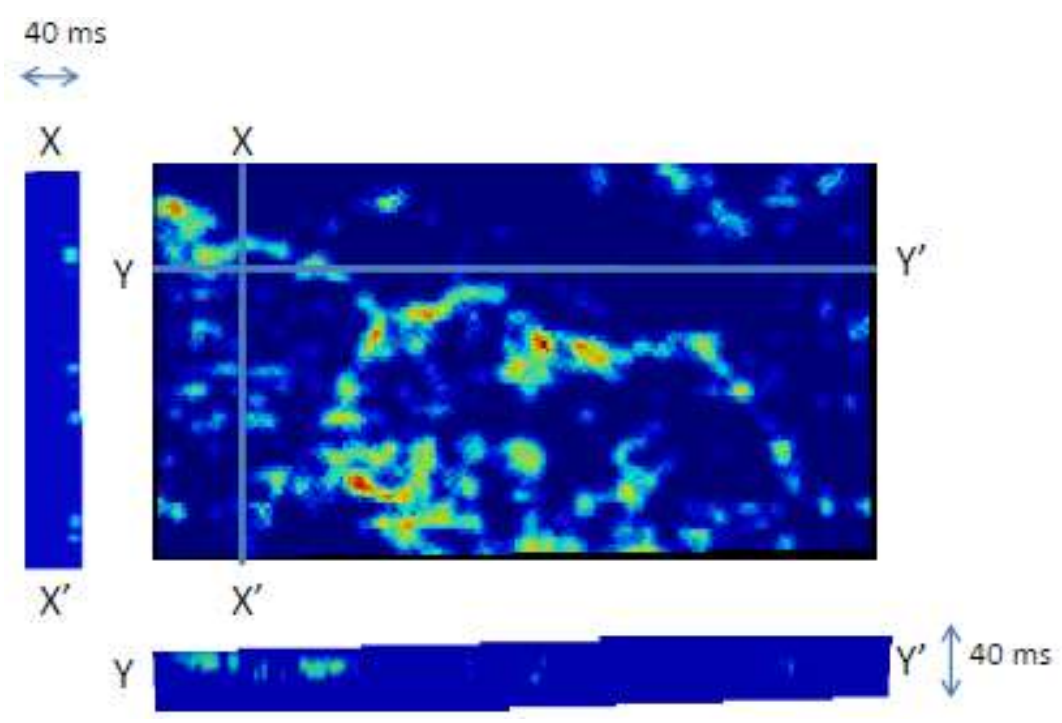

Figure 21 Cross section of Stratton Shallow Channel pseudo-impedance.

\section{Discussion and Conclusions}

It has been shown that maximum-minimum (m-m) attribute can resolve the reflector position of a wedge-modeled seismic. Regardless the magnitude estimated, $\mathrm{m}-\mathrm{m}$ attribute can be considered to be alternative in providing preliminary reflectivity, persistently, pseudo-reflectivity map. The provided map then can be further processed for complete seismic inversion.

Combining the m-m attribute with zero-INTENS-difference (z-i-d) attribute, estimating the true thickness of wedge-modeled seismic can be done accurately. When the synthetic seismic is constructed with a perfect wavelet, the thickness below tuning of the wedge is estimated precisely. Although perfect wavelet is only 'a myth' in real world, the evidence enables solution of estimating the layer thickness below tuning.

The z-i-d attribute cannot be found directly from the INTENS-difference profile when an imperfect wavelet is used to construct the synthetic seismic. The z-i-d attribute can be found statistically from INTENS-difference profile by finding the nearest-to-zero of the INTENS-difference profile value. Because of parabolic character of INTENS-difference profile, there are two zero which has to be chosen. $\mathrm{m}-\mathrm{m}$ ratio has been proposed as additional parameter to help decision making. When $\mathrm{m}-\mathrm{m}$ ratio is above $\mathrm{m}-\mathrm{m}$ attribute the second zero is chosen and the first zero is chosen when $\mathrm{m}-\mathrm{m}$ ratio is below $\mathrm{m}-\mathrm{m}$ attribute. 
Algorithm of thickness estimation using $\mathrm{m}-\mathrm{m}$ and $\mathrm{z}-\mathrm{i}-\mathrm{d}$ attribute can be extended for more than one layer. It may be the only one way, but iterating two consecutive layers thickness estimation can be used as multilayer thickness estimation in general. However more than 3 layers model has not been tested, the result indicates that the algorithm will still robust for inverting more than 3 layers model. The effect of more layer number still needs further observation.

Stratton shallow channel region pseudo-relative-impedance has mapped well by the extended method. The region is difficult to be mapped by conventional tracked (picked) horizon because the channel differs from it surrounding (non channel) is only $2 \mathrm{~ms}$ [6]. The cross section of pseudo-impedance (Figure 21) shows that the channel thickness is about $10 \mathrm{~ms}$ or less, which is below tuning which around 15 to $13 \mathrm{~ms}$. Although there is no well confirming the pseudoimpedance map, the method capability of delineating pseudo-relativeimpedance of Stratton shallow channel indicates that the method potential to characterize thin bed reservoir.

\section{References}

[1] Kallweith, R.S. \& Wood, L.C., The Limits of Resolution of Zero-phase Wavelets, Geophysics, 47(7), 1035-1046, 1982.

[2] Widess, M.B., How Thin Is Thin Bed?, Geophysics, 38(6), 1176-1180, 1973.

[3] Zang, H., How thin is a Thin Bed? An Alternative Perspective: The Leading Edge, 2009.

[4] Russel, B.H., Introduction to Seismic Inversion Methods: Society of Exploration Geophysicists, 1988.

[5] Chopra, S., Castagna, J. \& Portniaguine, O., Thin-bed Reflectivity Inversion, $75^{\text {th }}$ Annual International Meeting SEG, Expanded Abstract, 2057-2061, 2006.

[6] Pennington, D., \& Wayne, Calibration of Seismic Attributes for Reservoir Characterization, Annual Report, Department of Geological Engineering and Sciences Michigan Technological University, 2001.

[7] Puryear C.I. \& Castagna, J.P., An Algorithm for Calculation of Bed Thickness and Reflection Coefficients from Amplitude Spectrum, SEG/New Orleans 2006 Annual Meeting, 2006.

[8] Portniaguine, O., \& Castagna, J., Spectral Inversion: Lesson from Modeling and Boonesville Case Study: $75^{\text {th }}$ SEG Meeting, 1638-1641, 2005.

[9] Liu, J. \& Marfurt, K.J., Thin Bed Thickness Prediction Using Peak Instaneous Frequency, SEG/New Orleans 2006 Annual Meeting, 2006.

[10] Hall, M., Predicting Bed Thickness with Cepstral Decomposition: The Leading Edge, 2006. 
[11] Chung, H., \& Lawton, D., Some Properties of Thin Beds: SEG Expanded Abstracts 10, 224, 1991.

[12] Marangakis, A., Costain, J.K. \& Coruh, C., Use of Integrated Energy Spectra for Thin-Layer Recognition, Geophysics, 50(3), 495-500, 1985. 